\title{
Prosody in Interaction
}

\author{
Pia Bergmann (Duisburg-Essen)
}

\begin{abstract}
Interactional approaches to prosody have seen an enormous growth in the last decades. One crucial assumption common to these approaches is that prosodic devices may serve as resources for structuring and organizing an interaction. Methodologically, interactionally informed research of prosody rests upon ethnomethodological conversation analysis and contextualization theory. In this paper, a case study of the Cologne German rising-falling intonation contour serves to illuminate the prevalent methods in the field. The results are discussed with respect to their implications for basic theoretical assumptions about prosody and intonation. Consistent with core assumptions of Interactional Linguistics, they point to the variable and gradient nature of intonational functions that can best be captured in a grammar model that allows for holistic descriptions of linguistic structures.
\end{abstract}

\section{$1 \quad$ Introduction}

During the last decades, the intersection of prosody and interaction has developed into a field of vital interest for many scholars stemming from the background of Interactional Linguistics, Conversation Analysis, the Phonology for conversation approach, and others. Research covers a wide range of topics dealing with questions of how specific actions or styles are brought about, of how prosody relates to the display of affect, as well as with more general aspects like the construction of units or the organization of turn taking (cf. e. g. Auer/di Luzio 1992; Auer/Selting 2001; Barth-Weingarten/Reber/Selting 2010; Couper-Kuhlen/Selting 1996; Local/Wells/Sebba 1985; Local/Kelly/Wells 1986; Selting 1995; Selting/Couper-Kuhlen 2000; for an excellent overview of current research questions see Selting 2010).

Despite their differences in concrete research questions, most of the approaches in the realm of interactional prosody share some basic assumptions. First of all, the main aim of many studies lies in the description of prosodic means for the accomplishment of recurrent interactional tasks. Research in interactional prosody, as it is viewed in this article, thus takes up core assumptions from Interactional Linguistics - with a special focus on prosody. As a natural consequence of this aim, one basic methodological assumption that all scholars of prosody in interaction seem to agree upon is that all findings should ideally rely on empirical studies of naturally occurring spoken language. Moreover, the ways to approach the material are guided by several principles that were first spelled out by Couper-Kuhlen and Selting (1996) and that go back to methods common in ethnomethodological conversation analysis and contextualization research.

Linguistik online $88,1 / 18$ - http://dx.doi.org/10.13092/lo.88.4188

CC by 3.0 
In order to elucidate both the theoretical as well as the methodological aspects, the following introductory sections are dedicated to the theoretical background of interactional prosody (section 1.1) and to the prevalent methodological principles of the field (1.2). Section 2 will then exemplify some of the discussed issues on the basis of one study of German prosody (cf. Bergmann 2008).

\subsection{Theoretical background and basic concepts in interactional prosody}

As has been mentioned above, interactional prosody will be viewed as a specific branch of Interactional Linguistics in this paper. This section therefore sketches important ideas of Interactional Linguistics. It does not intend to give a full-fletched view of the theories that lie behind these ideas.

According to Selting and Couper-Kuhlen (2000: 77-79), Interactional Linguistics has its basis in ethnomethodological conversation analysis, contextualization research, and anthropological linguistics. Its main aims lie in the description of linguistic resources that fulfil important tasks for the participants of an interaction. Structures at all levels of linguistic description including prosody and multi-modality - are thus viewed as devices for the accomplishment of interactional tasks. As a continuation of this early descriptive focus of Interactional Linguistics, current works in the field have begun to approach the question of how (or if at all) the descriptive findings can be incorporated in usage-based models of grammar like Construction Grammar, Emergent Grammar, or Exemplar Theory (cf. Bybee 2001; Deppermann 2006; Hopper 2011; Pierrehumbert 2001). While work on prosody admittedly still lags behind a bit in this respect as compared to e. g. syntax, recently, efforts have been undertaken to fill this gap (see for example the contributions to Bergmann et al. 2012; Auer 2006; BarthWeingarten/Couper-Kuhlen 2011; Ogden 2010; Schweitzer et al. 2015).

The following paragraph turns to the most relevant aspects of ethnomethodological conversation analysis and contextualization theory. In ethnomethodological conversation analysis (cf. Auer 2013; Bergmann 1981; Liddicoat 2011; Sacks 1992), the ultimate goal is the reconstruction of participants" methods in making sense of social behaviour and interaction. In this approach, the participant's mind is conceived of as a black box so that mental processes are not transparent to anyone, not even to those interacting with each other. As a consequence, it is assumed that all interactants need to produce their contributions to the interaction in such a way as to make them interpretable to their co-participants who in the same way are again in the need to display their understanding of the utterance and to making their own contribution understandable. What follows from this is - from a methodological point of view - that the participants" efforts in making themselves understood are transparent not only to themselves but to the researcher, too. The researcher, thus, is in the position to reconstruct the means of sense-making by closely inspecting the participants" (re-)actions.

The need to transfer one's interpretation of every action to the surface and to thereby make it observable to the co-participants highlights the importance of the concepts of sequentiality and display of understanding (cf. Auer 2013: 144-148). It is only in its sequential succession that participant's interpretations of utterances can come to light, and neither the producer of the utterance nor an external observer can determine the meaning of the utterance by oneself. A good example in point are potentially ambiguous utterances whose interpretation is not 
fixed until the reaction of the co-participant has taken place. By way of an example, consider the following extract from a dialogue between a mother and her adult son. Prior to the extract, they are talking about the son's activities in athletic sports, which his mother does not appreciate: ${ }^{1}$

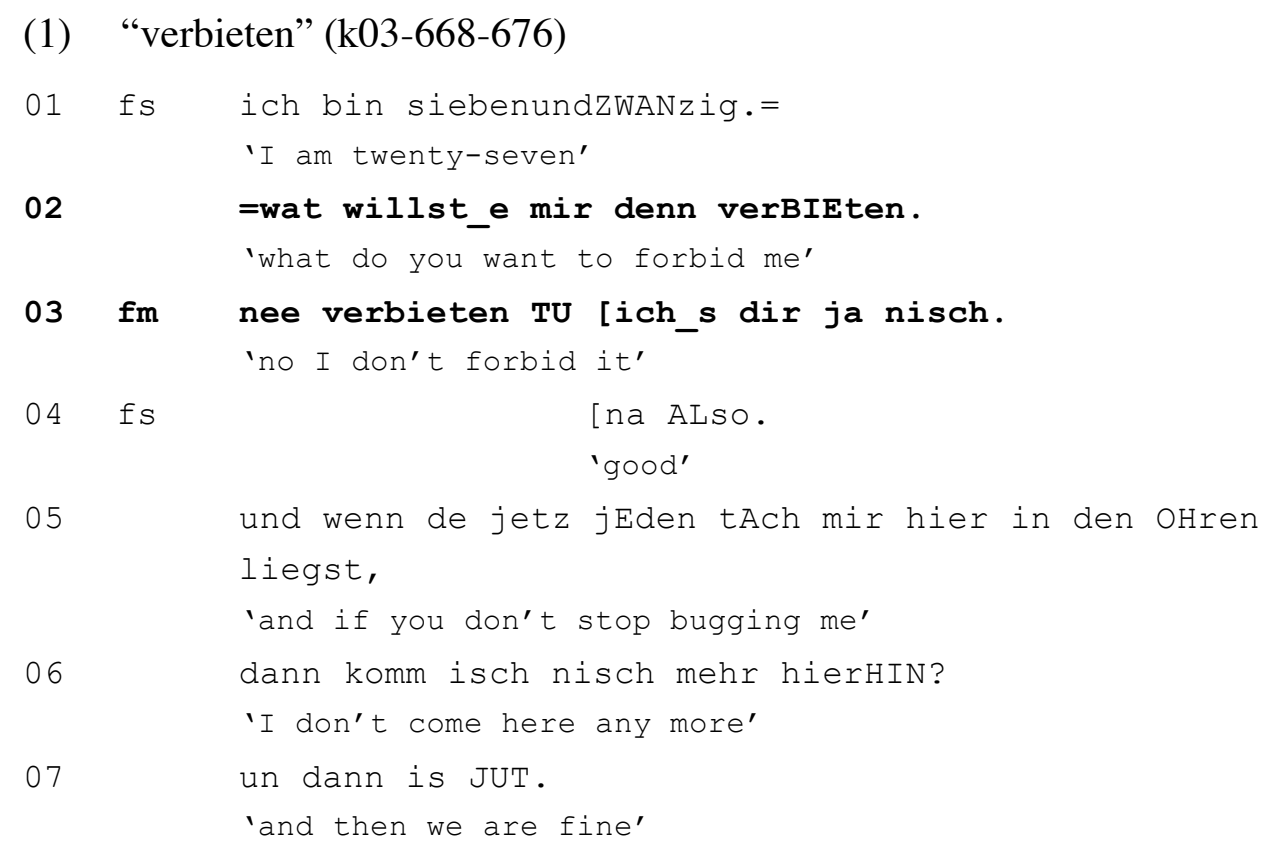

In line 02, the son (fs) produces an utterance that could be interpreted as a question when heard in isolation: Syntactically, it takes the shape of a prototypical wh-question in German. Prosodically, it is characterized by a falling final pitch movement, which is not unusual in wh-questions (cf. Selting 1995: 234). The reaction of fm (line 03) however, indicates that she does not treat the utterance as a question seeking for information but as a reproach: By denying that she wants to forbid her son from practicing she negates the presupposition of the "question" wat willst_e mir denn verbieten ('what do you want to forbid me') and thereby withdraws from the reproach of being too patronizing against her twentyseven-year-old son. Her reaction thus displays her understanding of the utterance as being a reproach. As can be seen from the reaction of her son, this understanding is not challenged but strongly confirmed when he first ratifies her withdrawal as (the only) adequate way to react (line 04, na ALso 'good') and then goes on to point out possible consequences if his mother should resume her undesirable behaviour (line 05-07). Closer inspection of the extract shows that fm's reaction seems strongly suggested as compared to a reaction that would treat her son's utterance as a mere information seeking question. By producing ich bin siebenundZWANzig ('I am twentyseven') first, fs makes relevant his (adult) age. The subsequent utterance necessarily pursues this relevance due to its adjacency within the same sequence. Hence, a reaction ignoring this aspect (like e. g. $d u$ sollst aufhören zu trainieren 'I want you to stop practicing') would probably lead to further expansions on this issue and not, as in the example, to ratification.

The example thus demonstrates that meaning is constructed by both (resp. all) participants of an interaction and in a step-wise manner. In addition to pointing to the relevance of sequentiality and display of understanding, we can glean even more details from this short extract.

\footnotetext{
${ }^{1}$ All extracts are transcribed according to GAT 2 (cf. Selting et al. 2009).
} 
These will lead us further into the direction of contextualization research, which - compared to ethnomethodological conversation analysis - takes a strong interest in interpretation processes conducted by the participants. It asks, what cues participants use in order to guide the interpretation of an utterance resp. in order to interprete an utterance. These contextualization cues typically are non-referential. I. e. prosodic or multimodal devices like intonation or speech quality, gaze or body posture gain in importance and become the centre of interest in many studies (cf. Auer 1992, 2013; Bergmann et al. 2012; Gumperz 1984).

Turning to example (1) again, we have observed already that the son's utterance is produced with a final fall in pitch. Although this pattern is not an impossible one for wh-questions, it may serve as a hint at the interpretation as a reproach. This hint, however, would not be perceivable as such if it was stripped from its context. Firstly, its sequential placement has to be taken into account, as has been explained above. Secondly, it is important to look at other cooccurring devices in the utterance itself. Here, we can state that the utterance contains the particle denn, which may serve as an intensifier in the given example. In this particular context, thus, the final falling pitch converges with other hints to indicate an interpretation that runs counter to that of an information seeking question. It serves as one contextualization cue next to others.

The assumption that contexualization cues often occur redundantly is another fundamental idea of contextualization research. What is more, it implies deeply rooted consequences for the conceptualization of the "meaning" of intonation. Intonational or other prosodic features are seen as carrying merely a meaning potential in contextualization research and subsequently in many studies in interactional prosody. On the contrary to that, formal approaches to intonation often aim at attributing fixed meanings to specific contours or tones. The following quote from Gussenhoven (1984) represents this position:

we should not be misled into assuming that intonational meaning is principally different from what we have so far believed linguistic meaning is like. It would be foolhardy [...] to assume that intonational meaning is variable, depends on other choices it combines with, and cannot therefore be given specific characterisations. If this was true, how would language be learnable? Just how many combinations of tune and text are there?

(Gussenhoven 1984: 197-198)

In strong opposition to this, contextualization research claims that intonational (or prosodic) meaning indeed is variable and "depends on other choices it combines with" (cf. ibd.). Additionally to example (1) discussed above, a case in point is the role of final intonation contours for the organization of speaker change. Section 2 will delve into more detail with this issue by demonstrating that the potential to indicate turn-holding varies in strength for a specific intonation contour depending on co-occurring devices on other linguistic levels of the utterance.

Before summing up, let me point out one more fundamental characteristic of the interactional approach to prosody. Since it takes as its starting point the search for interactional functions of prosody, the set of possibly relevant prosodic cues is per se not limited. That is, each prosodic cue based on pitch, loudness, duration, speech quality and many others can contribute to the organization of an interaction in multiple ways. Prosodic cues that "prove" their interactional relevance as a consequence are to be taken into account in an interactionally based grammar of a language. This claim cuts across a crucial distinction that many formal ap- 
proaches to prosody and intonation make, namely the distinction between linguistic and paralinguistic functions of prosody or intonation (cf. Gussenhoven 2004; Ladd 2008). In this view, grammar is divided in a phonological component with discrete and categorical prosodic elements on the one hand and in a phonetic component, through which gradient and variable phonetic structures are implemented (cf. Gussenhoven 2004: 58). The core element of grammar thus is constituted by abstract, categorical elements like tones that serve linguistic functions like prominence cueing or phrasing. Gradient features on the other hand, are transferred to phonetic implementation (cf. Gussenhoven 2004: 48-50). This is not to imply that interactional approaches to prosody should not acknowledge these linguistic functions of prosody. Rather, due to the focus on interaction, the scope of what is subsumed under "grammar" is widened to incorporate categorical linguistic functions and so-called paralinguistic functions at the same time.

This different view on "grammar" lies at the heart of Interactional Linguistics, and has already been formulated by Schegloff et al. (1996). They state that much work in "traditional" linguistic approaches rests on the assumption that "the primary organization of language is situated at the syntactic, semantic, lexical, and phonological levels, with only the surviving, unordered 'details' - the 'residual variation' - being referred to pragmatic or interactional "factors"” (Schegloff et al. 1996: 25-26). As an alternative, they suggest:

does it not make more sense, is it not theoretically more plausible, to suppose that interactional and pragmatic organizations play a primary and formative role, rather than a residual one, in the organization of conduct, including talk, and that grammar and syntax are, if not subordinate, then not more than coordinate with them, for example, by being among the available resources and practices informing the interactional and pragmatic organizations?

(Schegloff et al. 1996: 26)

From this perspective, thus, grammar emerges from interaction. Linguistic structures that systematically contribute to accomplishing tasks in interaction therefore should find their rightful place in the grammar.

To sum up, research in interactional prosody as a field of Interactional Linguistics has as its primary goal to describe the functions of prosody in naturally occurring interaction. It is based on the idea that every interaction is an outcome of shared effort by all participants involved who display their understanding of the ongoing interaction on the linguistic (and nonlinguistic) surface. In this view, prosodic cues are seen as resources to organize and conduct orderly interaction. Transcending the purely descriptive level, an interactional grammar tries to incorporate relevant prosodic cues and leaves behind the strict division into a phonological and a phonetic component that is still characteristic of some formal approaches to intonation and prosody.

\subsection{Methods in interactional studies of prosody}

The theoretical background outlined above does not come without consequences for the methods with which to investigate prosody in interaction. Referring back to Couper-Kuhlen and Selting (1996) and Local and Walker (2005), Selting (2010: 16) states five methodological principles that shall be reproduced here in their original form due to their still high relevance for researchers in the field: 
1. Give priority to the analysis of naturally occurring talk.

2. Treat the data as an integral part of the context in which it occurs.

3 . Treat the data as emergent in real time on ongoing interaction.

4. Ground analytic categories in the data itself.

[...]

5. Validate analytical categories by demonstrating participants‘ orientation to them.

(Selting 2010: 16)

The methodological principles reverbarate the analytical stance sketched in section 1.1 in 1) treating the data as inseparable from its interactional and sequential context (principles 2 and 3 ), and 2) in the claim not to impose analytical categories onto the interaction that are external to it and not made relevant by the participants themselves.

The question then arises, how can the participants" resources and categories safely be uncovered without recurring to one's own interpretation of what is going on in the discourse? A guideline to this analytical task is given in five pieces of evidence that Selting (2010:16) introduces under the heading number 4 of the cited methodological principles (again referring back to Couper-Kuhlen/Selting 1996 and Wootton 1989). The pieces of evidence to be used in the argumentation for a participant's resource or category are:

1. The relationship of the device to just prior turns.

2. Co-occurring evidence within the turn.

3. Subsequent treatment of the interactional device in question.

4. Discriminability of the interactional device.

5. Deviant cases in the use of the device.

(Selting 2010: 16)

In the discussion of extract (1), we already touched upon the pieces of evidence numbered a) to c) in this list. Evidence d) implies that the device in question should be discriminable from other devices in the same position. For example, an utterance final falling intonation pattern can be discriminated from and compared to an utterance final slightly rising intonation pattern in order to demonstrate that they serve different functions (e.g. turn-yielding vs. turnholding).

Evidence e) refers to examples where a certain device is not used in the expected way. This "unexpected" use of course has to be reconstructed from its impact on subsequent reactions from the interlocutors. This impact can be as subtle as a pause when e. g. participant 1 uses an otherwise turn-holding device but does not continue. Please note that this piece of evidence of course can only be employed when a "normal" use of the device can convincingly be established on the grounds of a large-enough data base. In general, the meaning and systematic use of all devices has to be derived from a data collection that should comprise enough instances of the device to allow for such a systematic analysis.

In principle, every research question in the field can start from one of two perspectives (cf. Selting 2010: 29-30): One can start with a certain function and wonder how it is brought about in interaction. Possible research questions taking this perspective are: How is turntaking achieved in a certain dialect (cf. Local/Kelly/Wells 1986; Local/Wells/Sebba 1985; Gilles 2005; Bergmann 2008)? How do interactants affiliate or disaffiliate with their coparticipants (cf. Ogden 2006, 2010)? How do particpants construct units (cf. Szczepek Reed 2012; Szczepek Reed/Raymond 2013), and many more. On the other hand, a research ques- 
tion can focus on a certain device, e. g. what are the prevalent functions of a certain intonation pattern in a given dialect (cf. Bergmann 2008; Kügler 2007), to what aims do participants use creaky voice in language X (cf. Ogden 2004), and so on.

Both perspectives have their pros and cons from a methodological point of view. Selting (2010: 29-30) points to the risks of a form-based approach that according to her lies in leading to unsatisfying analyses because often no common overarching function can be found for say a certain intonation contour. The result of such an analysis thus runs the risk of being particularistic, delving into many different functions and actions, but not giving a systematic picture from the interactional point of view. On the other hand, one might object that to start from functions or actions bears some risks as well. Since the analytic task to establish certain functions or actions is by no means a trivial one, data collections often comprise instances where one is not quite sure whether the given extract really constitutes a member of the category of interest, e. g. a reproach. Additionally, one has to be very cautious not to run into a circular argumentation by establishing actions on the grounds of exactly those devices that one wants to identify. With these risks in mind, however, many studies have proven the intersection of prosody and interaction to be a feasible and rewarding field of research. The next section aims to elucidate the outlined methodological and theoretical aspects on the basis of a case study of one specific intonation contour, the final rise-fall in Cologne German.

\section{Case study: Organizing turn-taking in Cologne German}

The case study to be reported in this section deals with the interactional functions of the final rising-falling intonation contour in Cologne German (cf. Bergmann 2008). The rise-fall has been described as an intonation contour characteristic for the Ripuarian area, specifically Cologne, by Gilles (2005), Peters (2006), and Bergmann (2008). A typical instance of the contour is given in figure 1; the contour is spread over the utterance die mAUer vom BAHNgelände ('the wall of the railway area'):

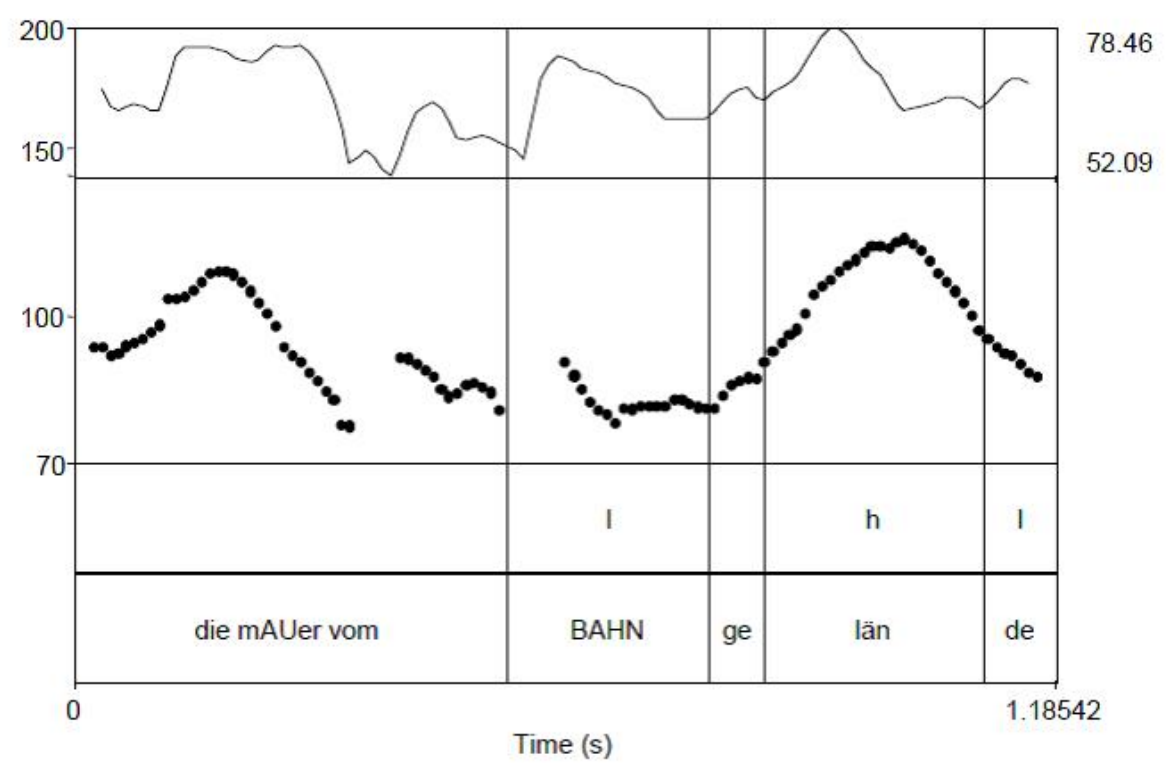

Figure 1: A prototypical instance of the Cologne German rise-fall 
After the first (pre-nuclear) high pitch accent on the syllable $m A U$ (from German Mauer 'wall'), pitch falls to a low level to the low nuclear pitch accent on $B A H N$ ('railway'). It then rises to a high tone on the syllable län (from German gelände 'area') before falling to a low level at the end of the intonational phrase.

In Bergmann (2008), 350 instances of this contour have been investigated with respect to formal and functional characteristics. The instances were taken from interview data that were gathered in the research project on dialect intonation at the Universities of Freiburg and Potsdam (funded by the German Research Foundation), from the first season of the reality-tv show "BigBrother" (broadcasted by RTL II in 1999), and from the reality-tv show (scripted reality) "Die Fußbroichs" (broadcasted by WDR in the early 1990ies).

In this paper, the focus of interest lies on the role the contour plays in the organization of turntaking in spontaneous speech. The guiding hypothesis is that the rise-fall takes on turnholding functions (cf. Gilles 2005; Peters 2006). However, it will be argued that this function - as basic as it may seem - cannot be stated across the board and without taking into accout co-occurring devices on other levels of linguistic description as well as the context of the contour and the actions carried out by the contour bearing utterance. The line of argumentation will rest upon the methods sketched in section 1.2.

The remainder of this section is organized as follows: First, a short introduction to turn-taking and unit construction will be given in order to set the stage for the discussion of the final risefall (2.1). Section 2.2 then exemplifies the use of the contour from a quantitative perspective. Specifically, it presents the co-occurrence pattern of the contour with other (non-prosodic) devices for turn-holding and based on these patterns pins down the occurrence of speaker change. Section 2.3 will progress to a qualitative analysis of the contour bearing utterances in question by focussing on those instances that seem to contradict the hypothesized turnholding potential of the final rise-fall in Cologne German.

\subsection{Unit construction and turn-taking}

The topic of turn-taking cannot be dealt with without introducing basic insights into the construction of units in spontaneous speech. This is due to the fact that speaker change does not occur haphazardly just anywhere in a conversation with two or more participants, but is orderly and interactionally achieved. The first to point to this issue were Sacks, Schegloff and Jefferson (1974) in their seminal paper on turn-taking in American English conversation. Since then, turn-taking is considered to be governed by two basic components: the turn construction component and the turn allocation component. Whereas the turn construction component mainly answers the question when a speaker change may occur, the turn allocation component is dedicated to the interactional task to choose who is going to be the next speaker. For the purposes of this paper, the turn allocation component is of subordinate importance and will therefore be left aside.

The turn construction component rests on the observation that speaker change occurs and recurs without leading to longer gaps or overlaps (i. e. portions of simultaneous speech). Such a fine-grained organization of participants ' contributions in time would seem highly unlikely if there were no systematic cues in the utterance underway to project possible entrance points for the current recipient. In conversation analysis, these possible entrance points are called 
transition relevant places (or TRPs). ${ }^{2}$ They constitute the end of a so-called turn constructional unit (or TCU). According to Auer (1996) and Selting (2000), turn construction is crucially based on devices from syntax and prosody:

A TCU is [...] a unit that is constituted and delimited by the interplay of syntax and prosody: it is constituted as a cohesive whole by the deployment of syntactic and prosodic construction schemata, and it ends with the co-occurrence of a possible syntactic and a possible prosodic unit completion in its sequential context.

(Selting 2000: 504)

While syntactical structures guide global projections with respect to the probable end of the on-going unit, prosodic cues are supposed to serve more local requirements when a syntactically projected possible TRP has been reached (cf. Auer 1996: 75; Selting 1995: 206-208). Given the interplay of syntax and prosody in unit construction, it is crucial to point to the important distinction between prosodic (or: intonational) completion on the one hand and turnholding vs. turn-yielding functions of intonation contours on the other hand: Intonational completion merely refers to the fact that an intonation unit or phrase is complete, i. e. it consists of at least one pitch accent syllable and a cohesive pitch contour (cf. Selting 1995: 3941). ${ }^{3}$ Speaking of turn-holding vs. turn-yielding intonation contours however implies intonational completion plus a specific final pitch movement that is related to the organization of turn-taking. For example, a syntactically complete utterance may at first sight seem to indicate that a TRP has been reached. An intonation contour with a slightly rising final pitch movement at the end of the utterance, however, may then serve as a hint that despite syntactic and prosodic completion, the current speaker wants to continue his or her turn. The intonation contour thus serves as a turn-holding device irregardless of its completeness.

Matters are further complicated by the fact that in addition to syntax and prosody, projecting devices on other levels, like lexico-semantics or semanto-pragmatics are relevant, too. This leads to simultaneous projections for continuation that are based on different linguistic levels and that may differ in scope. A case in point are the so-called big packages like conversational stories or jokes (cf. Selting 2000) where speakership is secured for the current speaker for an extended turn that stretches across more than one linguistically defined TCU. From a semanto-pragmatic perspective on the other hand, the TRP would not be reached until the very end of the big package. Without going into detail with this complicated issue, for this paper, we want to adhere to the solution proposed by Selting (2000: 487-489). In order to incorporate far reaching projections like those based on semanto-pragmatics, she introduces the notion of final TCUs. TCUs then are purely linguistic units defined by syntax and prosody as has been stated above. They may occur when projections based on other levels are still open, which would make them non-final TCUs, or they can occur when completion on all other levels has been reached, thus being final TCUs and leading to a TRP.

Another important consequence of the coexistence of different layers of projective forces lies in the fact that utterances can be "more or less" turn-holding. I. e. an utterance which is not yet complete due to open projections on all relevant linguistic levels (syntax, prosody, lexico-

\footnotetext{
2 It is important to note that these TRPs are just possible places (or rather points in time) for a speaker change to legitimately occur; a speaker change thus can but need not take place.

${ }^{3}$ For more information on the complex and controversial issue of intonational phrasing see Auer 2010, BarthWeingarten 2013, Bergmann and Mertzlufft 2009.
} 
semantics and semanto-pragmatics) will be less likely to be followed by a speaker change than an utterance with open projections on only one level, e. g. semanto-pragmatics. The relevance of the complexity of turn-holding devices for speaker change has been demonstrated by Ford and Thompson (1996) for English.

In Bergmann (2008), a similar line of argumentation is pursued in the discussion of the Cologne German rise-fall. Starting out with a data set of 307 rise-fall bearing declarative utterances, each utterance was analysed with respect to its turn-holding potential. To this end, additionally to syntactic completion, projection on the lexico-semantic level as well as on the semanto-pragmatic level were taken into account. The remainder of this section is dedicated to a brief introduction to these levels in order to prepare for the next section where the results of the co-occurrence pattern and its relation to the occurrence of speaker change will be illustrated.

First, consider extract (2) as an instance of a syntactically incomplete rise-fall bearing utterance (the rise-fall is indicated by the small letters beneath the utterance; $l$ refers to low pitch, $h$ to high pitch):

(2) Syntactic projection (k07-2222-2227)

01 k07 un wenn dann die schweren WAgen kamen

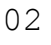

In this example, the contour bearing utterance occurs with a pre-positioned if-clause that projects the upcoming then-clause and therefore would be incomplete in isolation.

Extract (3) exemplifies a rising-falling utterance with a lexico-semantic turn-holding device:

(3) Lexico-semantic projection (k07-1382-1386)

01 k07 Erst mit der kleenen SIESCHfähre

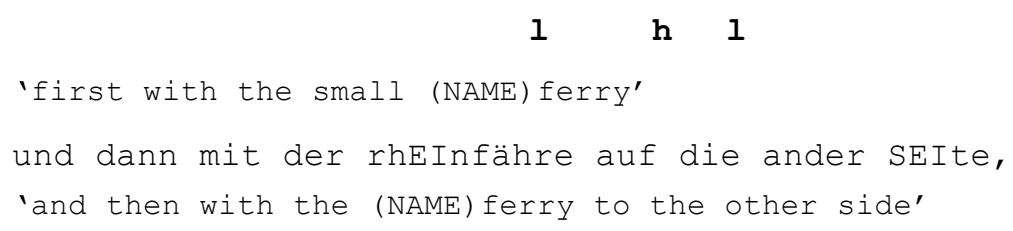

Here, erst ('first') introduces the first step in a succession of ferries to take when you travel alongside the rivers Sieg and Rhein. The word indicates that at least one other element is to follow in the list.

Finally, the next extract illustrates a case of incompleteness on the basis of semantopragmatics. The contour bearing utterance (line 5) introduces a (playful) argument for the speaker's earlier claim that the reason for meat being very cheap in Chinese restaurants is that they do not have to pay for it. 
(4) Semanto-pragmatic projection (bb72-1901-1911)

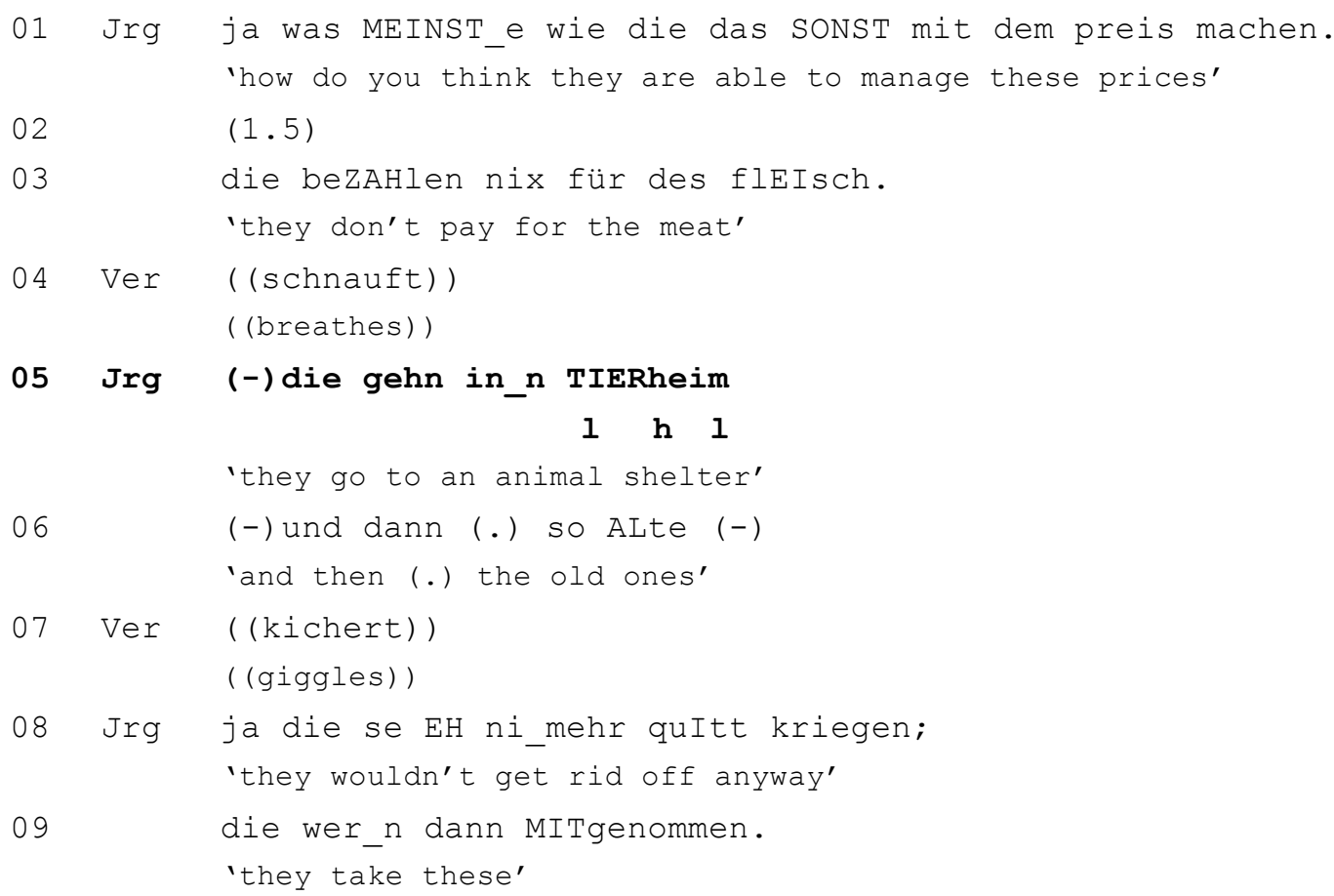

The utterance as such does not project continuation on syntactic or lexico-semantic grounds. Hence, considered in isolation, there would be no indication of a turn-holding potential. Seen in its specific context from a semanto-pragmatic point of view, however, the utterance does not reach a point of possible completion because it does not introduce but the first of several necessary steps to obtain the "meat" Jrg was speaking about earlier in the extract.

Given this basic information on the different devices for projecting turn continuation, the next section turns to the quantitative analysis of the co-occurrence pattern of the Cologne German rise-fall and its implications for speaker change.

\subsection{The rise-fall from a quantitative perspective: Co-occurrence and speaker change}

A central goal of the functional analysis of the rise-fall in Cologne German was to determine its role in turn-taking. Lead by the assumption that turn-holding potential is contextualized on more than one linguistic levels and that contextualization cues often occur redundantly, the first step to investigate the rise-fall's function for turn-taking was to establish a co-occurrence pattern for the contour. The pattern takes into account the linguistic levels described in section 2.1 , i. e. syntax, lexico-semantics and semanto-pragmatics. It has to be borne in mind that of course, the turn-holding devices on these levels may occur simultaneously, too, so that the turn-holding signal on a whole can be more or less complex. Not all possible combinations of the levels surfaced in the data, though: the rise-fall occurred together with turn-holding devices (1) on lexico-semantic and semanto-pragmatic basis (LS + SP), (2) on syntactic and semanto-pragmatic basis ( $\mathrm{S}+\mathrm{SP}$ ), and (3) on semanto-pragmatic basis (SP). Finally, it also occurred alone with no other turn-holding devices (none).

Figure 2 displays the resulting co-occurrence pattern for the rise-fall: 


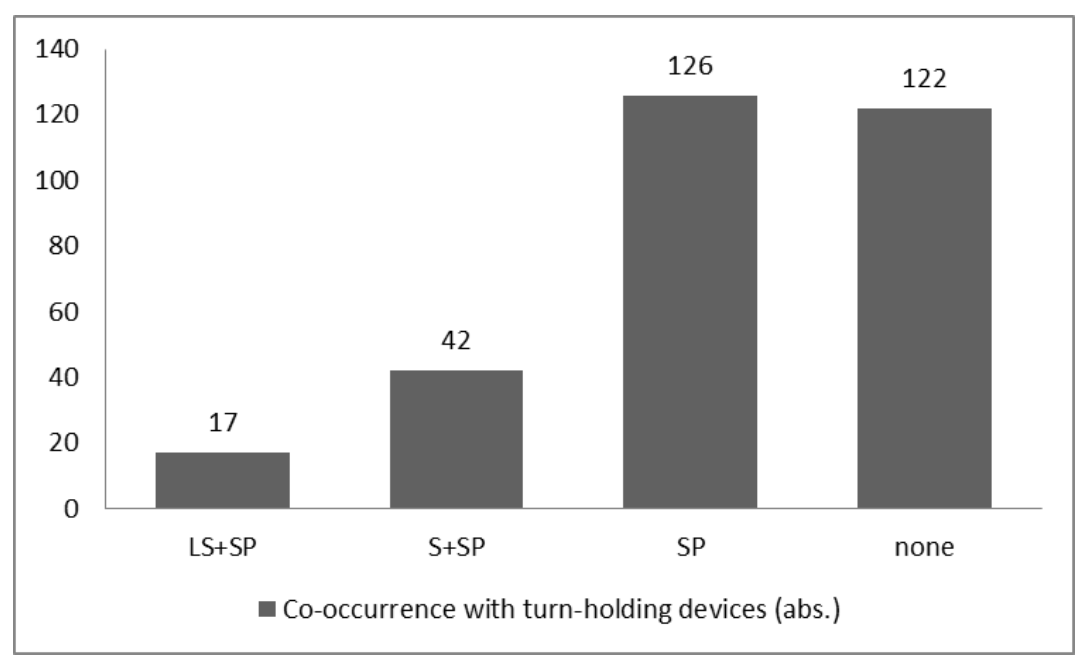

Figure 2: Co-occurrence pattern of the Cologne German rise-fall $(n=307)$

Of 307 instances of the rise-fall, 17 occurrences are combined with turn-holding on the lexico-semantic and semanto-pragmatic level and 42 instances are combined with syntactic and semanto-pragmatic turn-holding devices. Mostly, the rise-fall is combined with utterances that are incomplete for semanto-pragmatic reasons only $(n=126)$. An exclusive use of the rise-fall was observed in 122 cases. All in all, the distribution of the rise-fall indicates that cooccurrence with turn-holding on other levels outweighs the instances where the rise-fall is used alone: $60.3 \%$ of all rising-falling instances occur with one or more turn-holding devices as compared to $39.7 \%$ exclusive occurrences. This can be viewed as a first indication of a probable turn-holding function of the rise-fall in Cologne.

To check this preliminary conclusion, first, a comparison to slightly rising final intonation contours in the same data set was drawn. Slightly rising intonation contours are commonly considered as turn-holding (cf. Selting 1995). Interestingly, the 50 instances of final rises that were investigated, display a similar distribution as the final rise-fall: $66 \%$ of the instances cooccur with other turn-holding devices (SP: $46 \%$, S + SP: $18 \%$, LS + SP: $2 \%$ ), only $34 \%$ occur as sole indicator of turn-holding potential. From this noticeable resemblance we can draw an additional argument for the turn-holding potential of the rise-fall.

Despite these hints at the turn-holding function of the rise-fall, an even more convincing argument lies in the actual turn-taking behaviour of the participants of the interaction. All in all, 28 speaker changes occur after the rise-fall bearing utterances that constituted the data set $(\mathrm{n}=290)$. (Please note that 17 instances were excluded from the analysis due to occurrence in monologues). I. e. in only $9.1 \%$ of all rising-falling utterances, a speaker change is observed. This being a fairly low rate of speaker changes, results become more interesting when we additionally consider the distribution of speaker changes according to turn-holding complexity, which is demonstrated in figure 3 . 


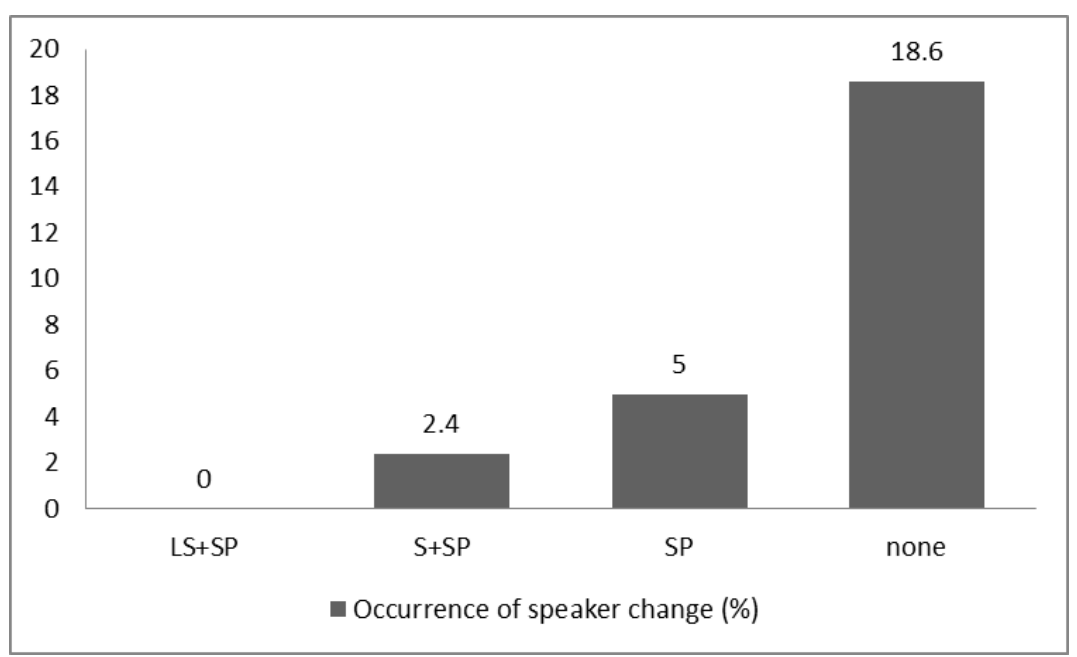

Figure 3: Speaker change $(n=28)$ according to co-occurence with turn-holding devices

The picture that emerges from figure 2 points to a rather unequal distribution of speaker changes according to turn-holding potential: Whereas no utterance of the category LS + SP and $2.4 \%(\mathrm{n}=1)$ resp. $5 \%(\mathrm{n}=6)$ of the categories $\mathrm{S}+\mathrm{SP}$ and SP are followed by a speaker change, $18.6 \%(\mathrm{n}=21)$ of all utterances without any non-intonational turn-holding device are followed by a speaker change. I. e. if a speaker change occurs at all it is most likely to be the case after a rising-falling utterance with no other turn-holding devices. Put differently, what we can conclude from this distribution is that intonation alone is a comparably weak indicator for turn-holding. Increasing turn-holding complexity on the other hand leads to fewer occurrences of speaker change. Still, including its co-occurrence pattern, the rise-fall can indeed be considered predominantly turn-holding.

As one last piece of evidence for the turn-holding function of the rise-fall in Cologne German, the distribution of speaker change after slightly rising, rising-falling and falling contour bearing utterances was taken into account. Included in the analysis were 50 cases of slightly rising contour bearing utterances and 50 cases of utterances with a final fall, all of which were characterized by no additional turn-holding devices on other linguistic levels. These were then compared to the rising-falling utterances of the category "none" as displayed above. Figure 4 illustrates the results for the distribution of speaker change according to final pitch movement.

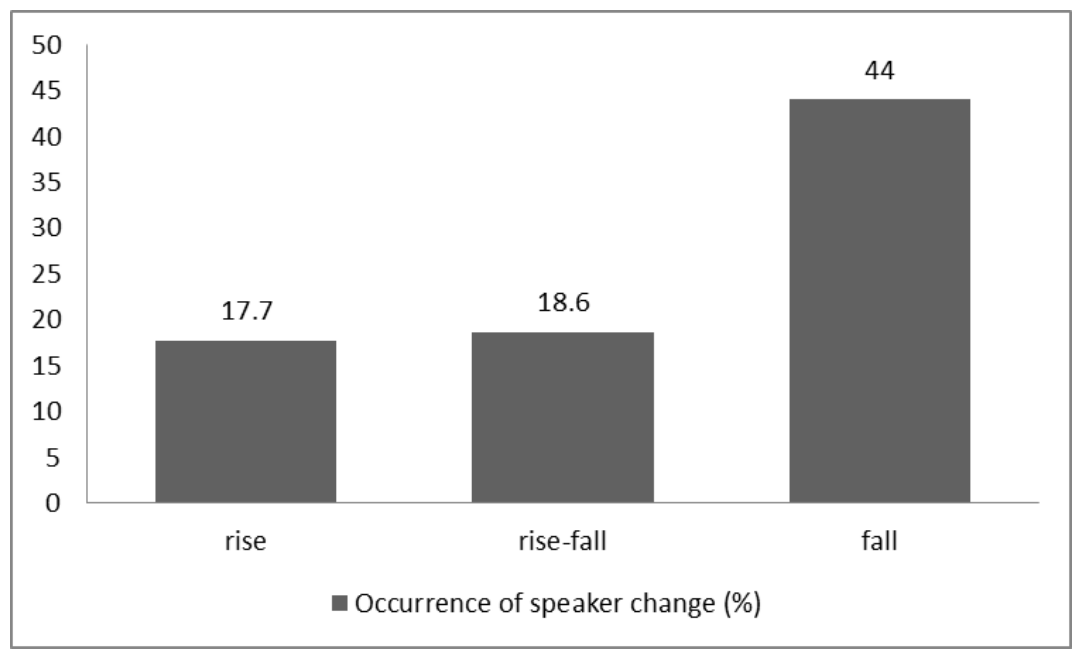

Figure 4: Speaker change after final rises, final rise-falls and final falls in Cologne German 
As is demonstrated in figure 3, the final rise and the final rise-fall lead to a similar percentage of speaker changes $(17.7 \%$ and $18.6 \%)$ as compared to final falls which are followed by a speaker change in $44 \%$ of all cases. First of all, this shows that intonation does have an influence on turn-taking. Everything else being equal with respect to turn-holding potential, the noteable difference in turn-taking is most likely to be attributed to the intonational design of the utterances. Additionally, the turn-holding potential of the rise-fall is once again confirmed by its similarity to the final slight rise.

Of course this also means that the final fall in the rise-fall does not have an extra effect with respect to turn-taking as compared to the simple (slight) rise. Approaching the issue from a more formal perspective one could ask whether the rise-fall and the rise could thus be considered some kind of "allocontours" of one turn-holding contour. If we were to take turn-taking as the sole criterion for establishing phonological distinctive functions for the nuclear pitch movements, this indeed seems to be a possible conclusion. However, to assign fixed functions or meanings to intonational elements per se does not seem to be feasible, as has been discussed above. Firstly, uttered in another context, the rise-fall may serve a turn-yielding function, and secondly, other interactional functions than turn-taking may be relevant functions of the contours for the participants of an interaction.

As a summary, we can state that the analysis of the Cologne German rise-fall by means of some of the methods established in interactionally informed prosody research (see 1.2) leads to the conclusion that the rise-fall fulfils turn-holding functions: It co-occurs with turnholding devices on other levels more often than not. Actual turn-taking behaviour of the participants shows that the rise-fall is followed by a speaker change in only $9.1 \%$ of all cases. Finally, the rise-fall can be discriminated from other final intonation contours and a comparison of the contour bearing utterances reveals a functional similarity between the rise-fall and the final slight rise. An additional conclusion that can be drawn from the analysis refers to a more general issue of intonational meaning or functions. Studying the impact of turn-holding complexity on actually occurring speaker change, it became obvious that intonation alone is a comparably weak indicator for turn-holding. Consequently, its function in turn-taking indeed seems to 'depend on other linguistic choices it combines with' (see section 1.1).

\subsection{The rise-fall from a qualitative perspective: Explanations for speaker change?}

This section turns to a qualitative analysis of rising-falling utterances. The qualitative analysis to be presented once again serves the goal to illuminate the contour's function in turn-taking. While the quantitative analysis strongly suggests that the contour is used as a turn-holding device by participants of the interaction, the speaker changes still pose a puzzle that should be addressed in more detail. At least two possible explanations for the occurrence of speaker changes come to mind: First, instances of speaker changes could be cases of unwarranted, competitive turn-taking. Then, the extracts should display signs of competitive behaviour and a struggle for the floor by the participants - and a general turn-holding function for the risefall was secured. Second, instances of speaker change could be reserved to specific contexts of use. As a consequence, the rise-fall could not be stated as a turn-holding contour across the board but rather we would have to acknowledge the fact that its function is context-bound. 
The in-depth analysis of all instances of the rise-fall leading to a speaker change reveals that indeed both types of explanations are valid. There are some specific, well-defined contexts where the rise-fall is systematically and recurrently used by the participants not as a turnholding but as a turn-yielding device. These contexts are conflict-oriented sequences with reproaches or arguments and sequences where language is produced concomitantly to an action like painting the walls or getting dressed. In the latter case, the contour bearing utterance serves as a comment to the ongoing action. Next to cases as these, however, there are few examples where turn-taking can indeed be considered competitive. In addition to these competitive instances, two other possibilities of speaker changes came up during the analysis that still speak for a turn-holding potential of the contour: First, there are cases where the incoming speaker collaboratively finishes the TCU of the previous speaker, i.e. cases of coconstructions after the rise-fall bearing utterance. And we encounter instances where the incoming speaker begins an insertion sequence, e. g. a question, after the resolution of which the first speaker comes back to the issue that was introduced by the rise-fall bearing utterance. In order to illuminate both the cases where the speaker change contradicts the interpretation of the rise-fall as a turn-holding device as well as those where the turn-holding function is corroborated, two instances were selected and will be discussed in more detail. ${ }^{4}$

The first instance exemplifies a speaker change after a rise-fall in the context of a reproach. It thus is an example of a rise-fall without turn-holding potential. It stems from the corpus "Die Fußbroichs". In the extract, fs comes to visit his girl friend (ft) and obviously expects her to having done the cooking already (extract (5)):

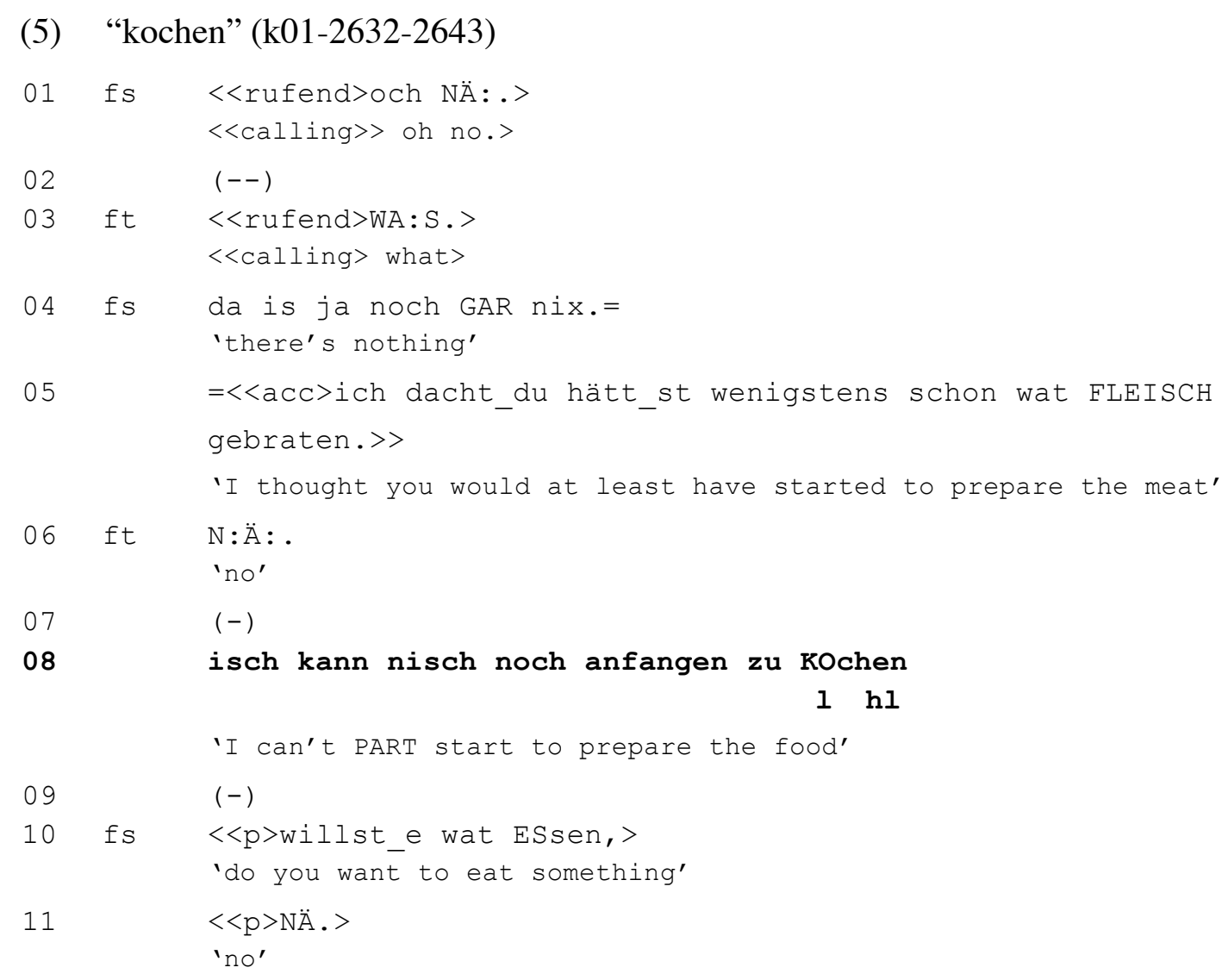

\footnotetext{
${ }^{4}$ For a detailed illustration of all examples the reader is referred to Bergmann (2008).
} 


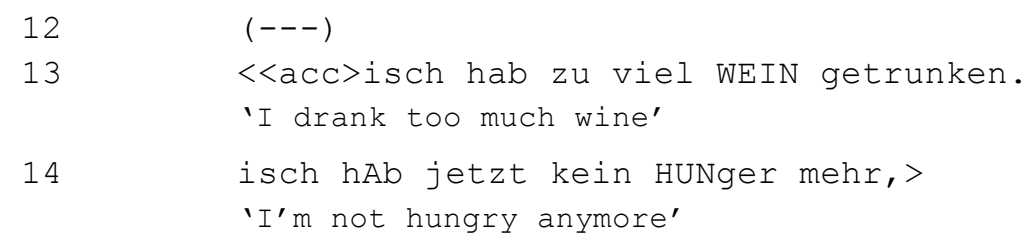

In line 5, fs explicitly states his expectation that $\mathrm{ft}$ would at least have started to prepare the meat by the time of his coming home. Ft negates that (line 6) and after a short pause gives an account for her behaviour, which carries the rising falling contour (line 8, isch kann nisch noch anfangen zu kochen 'I can't start to prepare the food [in addition to all the other things I am doing]'). This account highlights her opinion that fs' expectation is completely inadequate and thereby serves as a reproach against fs. It is again followed by a pause and a speaker change to fs who, however, does not directly address the reproach but shifts the topic and asks $\mathrm{ft}$ if she wants to eat something (line 10).

In this example there is no indication that the rise-fall bearing utterance was intended to hold the floor by ft. When fs takes the turn in line 10, there are no signs of competitive turn-taking behaviour. On the contrary, he speaks more softly than before, and ft accepts the topic shift by answering his question (line 11), likewise in a low voice.

The next example illustrates a case of a competitive speaker change after the rise-fall. It shows a discussion between Jrg and Sbr about the attractiveness of male and female homosexuals. While in the beginning, Jrg puts forward the opinion that contrary to male homosexuals, female homosexuals are not very attractive, Sbr tries to make the point that lesbian women are masculine (line 10,11) (extract (6)).

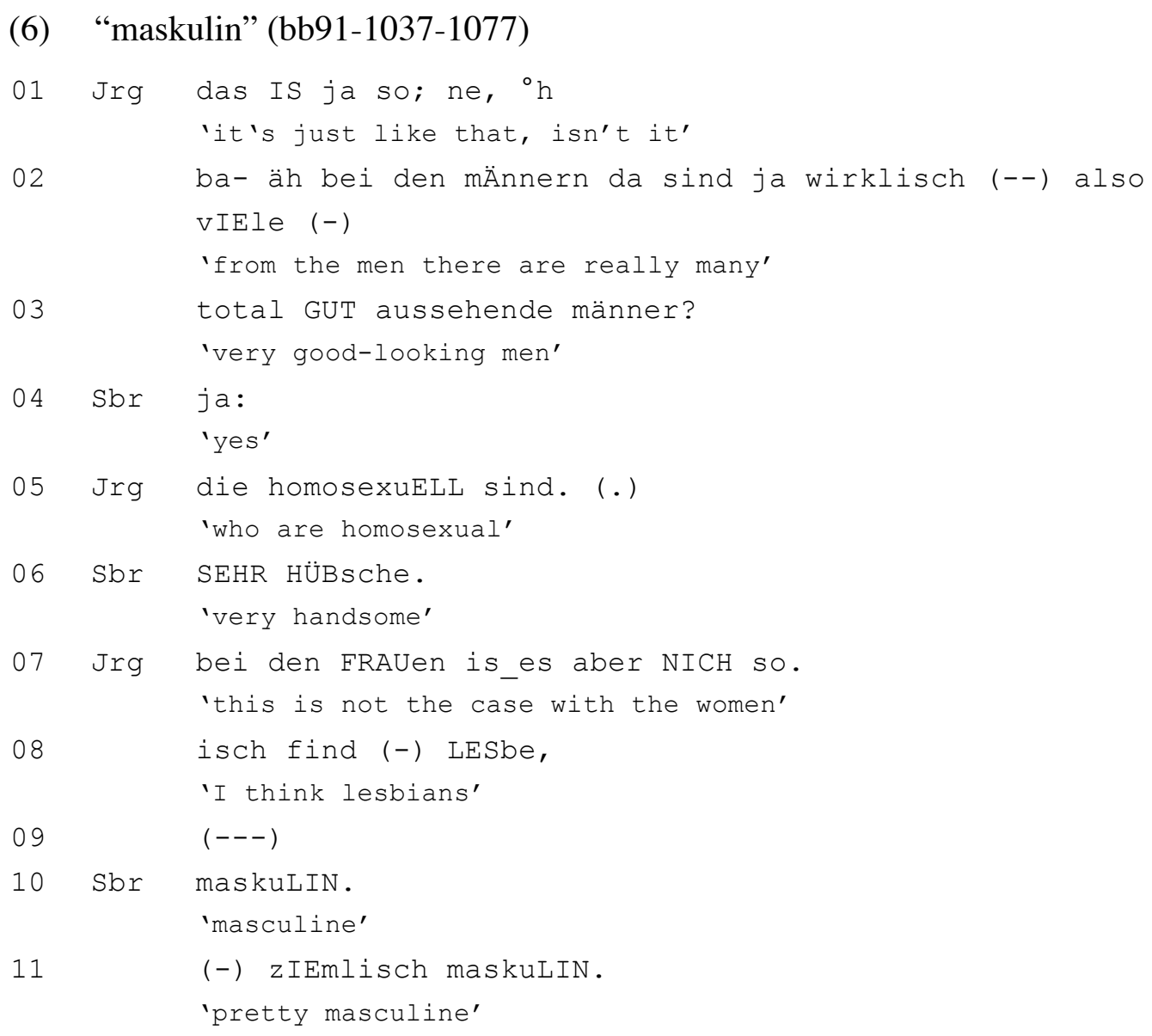




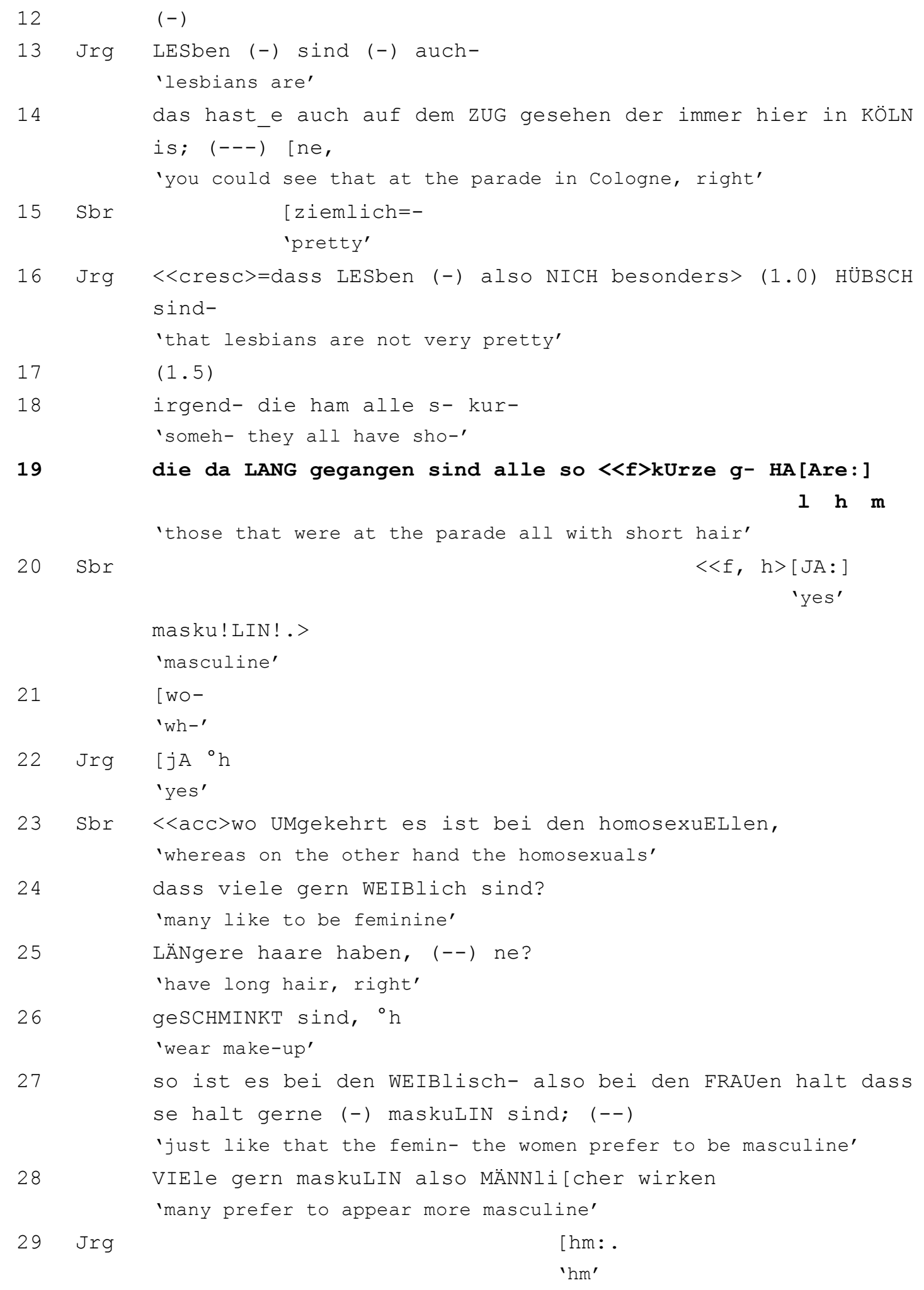

The contour bearing utterance is produced by Jrg (line 19). It serves as an illustration of his claim that lesbian women are not very pretty (line 16) and describes women he has seen at a parade in Cologne by means of the characteristic kurze HAAre ('short hair'). Sbr comes in in overlap with this utterance (line 20). She agrees with his description (JA: 'yes') and continues her contribution with masku!LIN! ('masculine'). Contrary to the example given in extract (5), this extract carries several signs of competitive turn-taking behaviour: Jrg already raises his voice at the end of the contour bearing utterance (line 19), when Sbr comes in with raised 
voice on a high pitch level, additionally, the vowels are lengthened and the accent on maskulin is characterized by strong pitch movement (line 20). The context prior to the rising-falling utterance furthermore reveals that Sbr had started two (or even three) earlier attempts to introduce the aspect of masculinity in the conversation (line 10, line 11 and [probably] line 15) without leading to an uptake by Jrg. Jrg's description of the women as having short hair then is used by Sbr to finally bring in this aspect on which she elaborates in further succession of the conversation (lines 23 to 28), once again with some indications of competitive speaker change (overlapping speech in lines 21 and 22 and increased speech rate in line 23). With this example, we thus encounter a speaker change after a rising-falling utterance that can be attributed to competitive turn-taking behaviour. It therefore does not conflict with a general turn-holding potential of the rise-fall.

The aim of this section was to further discuss the role of the Cologne German rise-fall for turn-taking. This was done by explicitly taking into account those instances of the rise-fall that seem to contradict the assumption that the rise-fall serves turn-holding functions in Cologne German as was established on the basis of the quantitative analysis (section 2.2): All instances were characterized by a speaker change after the rise-fall bearing utterance. The outline above demonstrated that the instances fall into two categories. One category where nothing in the behaviour of the participants hints to the fact that the rising-falling utterance was intended to be turn-holding. Instead, these realizations of the rise-fall occurred on specific actions in well-defined interactional contexts. The second category includes cases where a turn-holding potential can be reconstructed from the interaction despite actually leading to a speaker change, like e. g. competitive turn-taking behaviour or co-constructions. The discussion thus underlined the necessity to complement a more quantitative analysis by an in-depth qualitative investigation of the prosodic cue of interest.

\section{$3 \quad$ Summary and conclusions}

This paper aimed to introduce into the research field of prosody in interaction. It concentrated on the strand of research in the realm of Interactional Linguistics. Therefore, we started out with a short outline of the theoretical background of Interactional Linguistics (section 1.1) and the methods common in the field (1.2). The introductory section was followed by a case study of a typical Cologne German intonation contour and its function for turn-taking (section 2). Due to the focus on intonation, other prosodic cues like voice quality, loudness or duration did not gain much attention. And even for intonation, we did not touch upon but one characteristic, i. e. the final intonation contour in an intonation phrase. Likewise, from the perspective of interactional functions, many aspects were left untouched due to the concentration on the turn-taking system. Both from a formal perspective as well as from a functional perspective, thus, important aspects were left aside. This neglect is not to be read as a statement concerning the relevance (or irrelevance) of the different aspects. As was stated above, from an interactional point of view, there is no a priori reason to give one cue primacy over another. As long as a prosodic cue can be reconstructed as serving recurrent interactional tasks, it is deemed just as important as any other device with functions as such.

The case study highlighted two important issues in interactional prosody research: First, it demonstrated how interactional functions of prosody can be reconstructed from naturally oc-

ISSN 1615-3014 
curring conversation without relying on one's own intuitions. Rather, by making use of several methodological devices from interactionally informed research - like co-occurrence patterns for the prosodic cue in question, the reaction of the participants themselves to the prosodic cue, discrimination from and comparison with other prosodic cues and the investigation of deviant cases - we were able to argue for a turn-holding function of the intonation contour. Moreover, it could be shown that the turn-holding function varies in strength depending on its combination with turn-holding devices on other linguistic levels. Additionally, it was not valid for all instances of the rise-fall. Under specific interactional and contextual conditions, the Cologne German rise-fall cannot be reconstructed as having turn-holding potential but turnyielding potential rather.

These specifications lead us to the second important issue, which lies in the theoretical consequences that result from the findings. Given the fact that the rise-fall unfolds its turn-holding potential to different degrees and vascillates between turn-holding and turn-yielding depending on its context, we have a strong case to argue for a holistic and context-bound strategy of meaning-making in discourse. From an interactional point of view, it does neither seem feasible nor desirable to abstract away from the gradience and variation in intonational functions that we encounter in everyday talk. So, opposed to more formal approaches to intonation as introduced in section 1.1, the ultimate goal would not to be to pin down abstract meanings or functions for certain contours or tones and to neatly tell apart the phonetic from the phonological, but rather to build a grammar model that would be capable to incorporate and predict just that variation and gradience. Gussenhoven"s legitimate question of "how would language be learnable" (cf. Gussenhoven 1984: 198) quoted above should thus not be left unanswered. More recent developments in the realm of usage-based grammar models like Construction Grammar (cf. Auer 2006; Deppermann 2006) or specifically Exemplar Theory (cf. Pierrehumbert 2001; Schneider et al. 2015) seem to lend themselves quite well to tackle this issue. For the time being, we still are at the very beginning to understand how prosody could feature in accounts as these. Future research may bring us a step further towards this understanding.

\section{References}

Auer, Peter (1992): "Introduction: John Gumperz' approach to contextualization". In: Auer, Peter/di Luzio, Aldo (eds.): The contextualization of language. Amsterdam, Benjamins: 138.

Auer, Peter (1996): "On the prosody and syntax of turn continuations". In: Couper-Kuhlen, Elizabeth/Selting, Margret (eds.): Prosody in conversation. Cambridge, Cambridge University Press: 57-100.

Auer, Peter (2006): „Construction grammar meets conversation: Einige Überlegungen am Beispiel von „so“-Konstruktionen“. In: Günthner, Susanne/Imo, Wolfgang (eds.): Konstruktionen in der Interaktion. Berlin, de Gruyter: 291-314.

Auer, Peter (2010): „Zum Segmentierungsproblem in der Gesprochenen Sprache“. In: InLiSt - Interaction and Linguistic Structures 49: 1-19. www.inlist.uni-bayreuth.de/issues/49/In List49.pdf [23.10.2017].

Auer, Peter (2013): Sprachliche Interaktion. Eine Einführung anhand von 22 Klassikern. 2. Auflage. Tübingen: Niemeyer. 
Auer, Peter/Selting Margret (2001): „Der Beitrag der Prosodie zur Gesprächsorganisation“. In: Klaus Brinker et al. (eds.): Text- und Gesprächslinguistik. Berlin, de Gruyter: 11221131. (= HSK 16/2).

Barth-Weingarten, Dagmar/Couper-Kuhlen, Elizabeth (2011): “Action, prosody and emergent construction: The case of and". In: Auer, Peter/Pfänder, Stefan (eds.): Constructions: Emergent or emerging? . Berlin, de Gruyter: 263-292.

Barth-Weingarten, Dagmar/Reber, Elisabeth/Selting, Margret (eds.) (2010): Prosody in interaction. Amsterdam: Benjamins.

Barth-Weingarten, Dagmar (2013): “From ‘intonation' units to cesuring - an alternative approach to the prosodic-phonetic structuring of talk-in-interaction". In: Szczepek Reed, Beatrice/Raymond, Geoffrey (eds.): Units of talk - units of action. Amsterdam, Benjamins: 91-124.

Bergmann, Jörg (1981): „Ethnomethodologische Konversationsanalyse“. In: Schröder, Peter/Steger, Hugo (eds.): Dialogforschung. Düsseldorf, Pädagogischer Verlag Schwann: 952.

Bergmann, Pia (2008): Regionalspezifische Intonationsverläufe im Kölnischen. Formale und funktionale Analysen steigend-fallender Konturen. Tübingen: Niemeyer.

Bergmann, Pia et al. (2012): Prosody and embodiment in interactional grammar. Berlin: de Gruyter.

Bergmann, Pia/Mertzlufft, Christine (2009): „Die Segmentierung spontansprachlicher Daten in Intonationsphrasen. Ein Leitfaden für die Transkription“. In: Birkner, Karin/Stukenbrock, Anja (eds.): Die Arbeit mit Transkripten. Mannheim, Verlag für Gesprächsforschung: 83-95. www.verlag-gespraechsforschung.de/2009/pdf/transkri pte.pdf [23.10.2017].

Bybee, Joan (2001): Phonology and language use. Cambridge: Cambridge University Press.

Couper-Kuhlen, Elizabeth/Selting, Margret (1996): “Towards an interactional perspective on prosody and a prosodic perspective on interaction”. In: Couper-Kuhlen, Elizabeth/Selting, Margret (eds.): Prosody in conversation. Cambridge, Cambridge University Press: 11-56.

Deppermann, Arnulf (2006): „Construction Grammar - Eine Grammatik für die Interaktion?“. In: Deppermann, Arnulf/Fiehler, Reinhard/Spranz-Fogasy, Thomas (eds.): Grammatik und Interaktion. Untersuchungen zum Zusammenhang von grammatischen Strukturen und Gesprächsprozessen. Radolfzell, Verlag für Gesprächsforschung: 43-66. http://www.verlaggespraechsforschung.de/2006/pdf/grammatik.pdf [23.10.2017].

Ford, Cecilia E./Thompson, Sandra A. (1996): "Interactional units in conversation: syntactic, intonational, and pragmatic resources for the management of turns". In: Ochs, Elinor et al. (eds.): Interaction and grammar. Cambridge, Cambridge University Press: 134-184.

Gilles, Peter (2005): Regionale Prosodie im Deutschen. Variabilität in der Intonation von Abschluss und Weiterweisung. Berlin: de Gruyter.

Gumperz, John (1984): Discourse strategies. Cambridge: Cambridge University Press.

Gussenhoven, Carlos (1984): On the grammar and semantics of sentence accents. Dordrecht: Foris.

Gussenhoven, Carlos (2004): The phonology of tone and intonation. Cambridge: Cambridge University Press. 
Hopper, Paul (2011): "Emergent grammar and temporality in interactional linguistics". In: Auer, Peter/Pfänder, Stefan (eds.): Constructions: Emergent or emerging? Berlin, de Gruyter: 22-44.

Kügler, Frank (2007): Intonational phonology of Swabian and Upper Saxon German. Tübingen: Niemeyer.

Ladd, Robert (2008): Intonational phonology. $2^{\text {nd }}$ ed. Cambridge: Cambridge University Press.

Liddicoat, Anthony J. (2011): An introduction to conversation analysis. London: Continuum.

Local, John/Kelly, John/Wells, William H. G. (1986): “Towards a phonology of conversation: Turn-taking in Tyneside English". Journal of Linguistics 22: 411-437.

Local, John/Walker, Gareth (2005): "Methodological imperatives for investigating the phonetic organization and phonological structures of spontaneous speech". Phonetica 62: 120 130.

Local, John/Wells, William H. G./Sebba, Mark (1985): "Phonology for conversation. Phonetic aspects of turn delimitation in London Jamaican". Journal of Pragmatics 9: 309-330.

Ogden, Richard (2004): "Non-modal voice quality and turn-taking in Finnish". In: CouperKuhlen, Elizabeth/Ford, Cecilia E. (eds.): Sound patterns in interaction. Amsterdam, Benjamins: 29-62.

Ogden, Richard (2006): "Phonetics and social action in agreements and disagreements". Journal of Pragmatics 38: 1752-1775.

Ogden, Richard (2010): "Prosodic constructions in making complaints". In: BarthWeingarten, Dagmar/Reber, Elisabeth/Selting, Margret (eds.): Prosody in interaction. Amsterdam, Benjamins: 81-103.

Peters, Jörg (2006): Intonation deutscher Regionalsprachen. Berlin: de Gruyter.

Pierrehumbert, Janet (2001): "Exemplar dynamics: Word frequency, lenition and contrast". In: Bybee, Joan/Hopper, Paul (eds.): Frequency and the emergence of linguistic structure. Amsterdam, Benjamins: 137-158.

Sacks, Harvey (1992): Lectures on Conversation. Vol. 1/2, ed. by Gail Jefferson. Oxford: Blackwell.

Sacks, Harvey/Schegloff, Emanuel/Jefferson, Gail (1974): "A simplest systematics for the organization of turn-taking for conversation". Language 50: 696-735.

Schegloff, Emanuel/Ochs, Elinor/Thompson, Sandra (1996): "Introduction". In: Ochs, Elinor et al. (eds.): Interaction and grammar. Cambridge, Cambridge University Press: 1-51.

Schweitzer, Kathrin et al. (2015): "Exploring the relationship between intonation and the lexicon: Evidence for lexicalised storage of intonation". Speech Communication 66: 65-81.

Selting, Margret (1995): Prosodie im Gespräch. Tübingen: Niemeyer.

Selting, Margret (2000): "The construction of units in conversational talk". Language in Society 29: 477-517.

Selting, Margret (2010): "Prosody in interaction: State of the art". In: Barth-Weingarten, Dagmar/Reber, Elisabeth/Selting, Margret (eds.): Prosody in interaction. Amsterdam, Benjamins: 3-40.

Selting, Margret/Couper-Kuhlen, Elizabeth (2000): „Argumente für die Entwicklung einer ,interaktionalen Linguistik““. Gesprächsforschung - Online-Zeitschrift zur verbalen Inter- 
aktion 1: 76-95. www.gespraechsforschung-online.de/fileadmin/dateien/heft2000/ga-seltin g.pdf [16.07.2017].

Selting, Margret et al. (2009): „Gesprächsanalytisches Transkriptionssystem 2 (GAT 2)“. Gesprächsforschung. Online-Zeitschrift zur verbalen Interaktion 10: 353-402. www.gesprae chsforschung-online.de/fileadmin/dateien/heft2009/px-gat2.pdf [16.07.2017].

Szczepek Reed, Beatrice (2012): "Prosody, syntax and action formation: Intonation phrases as 'action components'”. In: Bergmann, Pia et al. (eds.): Prosody and embodiment in interactional grammar. Berlin, de Gruyter: 142-169.

Szczepek Reed, Beatrice/Raymond, Geoffrey (eds.) (2013): Units of talk - units of action. Amsterdam: Benjamins.

Wootton, Anthony J. (1989): "Remarks on the methodology of conversation analysis". In: Roger, Derek/Bull, Peter (eds.): Conversation: An interdisciplinary perspective. Clevedon, Multilingual Matters: 238-258. 